\title{
Ultratrace determination of uranium and plutonium by nano-volume flow injection double-focusing sector field inductively coupled plasma mass spectrometry (nFI-ICP-SFMS)
}

\author{
Dirk Schaumlöffel, ${ }^{b}$ Pierre Giusti, ${ }^{b}$ Myroslav V. Zoriy, ${ }^{a}$ Carola Pickhardt, ${ }^{a}$ \\ Joanna Szpunar, ${ }^{b}$ Ryszard Łobiński ${ }^{b c}$ and J. Sabine Becker*a \\ ${ }^{a}$ Central Division of Analytical Chemistry, Research Centre Jülich, D-52425 Jülich, Germany. \\ E-mail: s.becker@fz-juelich.de; Fax: +49 2461 612560; Tel: +492461612698 \\ ${ }^{\boldsymbol{b}}$ Group of Bio-Inorganic Analytical Chemistry, CNRS UMR 5034, Hélioparc, 2, \\ Av. Pr. Angot, F-64053 Pau, France \\ ${ }^{c}$ Department of Analytical Chemistry, Warsaw University of Technology, \\ 00-664 Warsaw, Poland
}

Received 27th July 2004, Accepted 18th November 2004

First published as an Advance Article on the web 3rd December 2004

A sensitive analytical procedure based on nano-volume flow injection (FI) and inductively coupled plasma double-focusing sector field mass spectrometry (ICP-SFMS) was developed for the ultratrace determination of uranium and plutonium. A 54-nl sample was injected by means of a nanovolume injector into a continuous flow of carrier liquid at $7 \mu \mathrm{min}^{-1}$ prior to ICP-SFMS. The absolute detection limits were $9.1 \times$ $10^{-17} \mathrm{~g}\left(3.8 \times 10^{-19} \mathrm{~mol}, \sim 230000{ }^{238} \mathrm{U}\right.$ atoms $)$ and $1.5 \times 10^{-17} \mathrm{~g}\left(6 \times 10^{-20} \mathrm{~mol}, \sim 38000{ }^{242} \mathrm{Pu}\right.$ atoms $)$ for uranium and plutonium, respectively. The method was validated for the determination of the uranium isotope ratios by the analysis of a certified isotope reference material (NIST U350). The analysis of a contaminated urine sample showed the enriched uranium to be the origin of contamination. Another application concerned the determination of plutonium at the subfemtomolar level in water with a detection limit down to the $\mathrm{ag} \mathrm{ml}^{-1}$ range $\left(6 \times 10^{-18} \mathrm{~g} \mathrm{ml}^{-1}\right)$.

\section{Introduction}

The characterization of highly radioactive nuclear materials and of radioactive waste for final storage with regard to longlived radionuclides is a challenging area of analytical chemistry. ${ }^{1,2}$ The determination of ultratrace concentrations and precise isotope ratio measurements of uranium and plutonium is also required in environmental monitoring, nuclear forensic studies and health control. Isotope ratio measurements of uranium (e.g., of depleted uranium or the evidence of ${ }^{236} \mathrm{U}$ ) and plutonium in the environment or in body fluids can help distinguish different sources of nuclear contamination such as, for example, global fallout from nuclear weapons testing, nuclear power plants or nuclear accidents. ${ }^{3-6}$

Inductively coupled plasma mass spectrometry (ICP-MS) has grown into a suitable analytical technique and a valid alternative to radioanalytical techniques for the determination of actinides owing to its high sensitivity and the possibility of isotope ratio measurements at the ultratrace level. In comparison with $\alpha$-spectrometry smaller size samples can be analyzed by ICP-MS and the time-consuming and labor-intensive chemical separation and enrichment procedures can be largely reduced or eliminated. In addition, ${ }^{239} \mathrm{Pu}$ and ${ }^{240} \mathrm{Pu}$ isotopes, which are difficult to analyze by $\alpha$-spectrometry due to the similar $\alpha$ energies of ${ }^{239} \mathrm{Pu}$ and ${ }^{240} \mathrm{Pu}(5.24$ and $5.25 \mathrm{MeV}$, respectively), can be easily determined by ICP-MS in a separated plutonium fraction or when the uranium hydride formation (possible interference of ${ }^{238} \mathrm{U}^{1} \mathrm{H}^{+}$at ${ }^{239} \mathrm{Pu}^{+}$) is eliminated. $^{7,8}$ Thermal ionisation mass spectrometry (TIMS) has been used as the dominant analytical technique for precise isotope ratio measurements for many decades. Especially TIMS with multiple ion collectors is generally the method of choice for isotope ratio measurements with high precision (down to $0.002 \%$ ). ${ }^{9}$ Nowadays, TIMS is more and more being replaced by ICP-MS due to the latter's excellent sensitivity, precision and good accuracy for isotope ratio measurements with practically no restriction with respect to the ionisation potential of the element investigated. ${ }^{10}$ Furthermore, the efficiency of ICP-MS is significant higher than that of TIMS, because many samples can be measured in a short time at lower cost.

A rapidly growing field of trace element determination involves the analysis of micro- or nanolitre sample volumes which is of particular concern when an amount of few milligrams only of a rare, toxic or radioactive sample is available. ${ }^{11}$ Microanalytical techniques coupled with increasingly sensitive ICP-MS offer a new tool for the determination of radionuclides and their isotope ratios in radioactive materials in order to reduce the handled radioactivity, to minimize the radioactive waste of an analytical procedure, the irradiation dose of the operator or a possible contamination of instruments with radioactive substances. ${ }^{2}$ Sample introduction into ICP-MS using several types of micronebulizer operating at low uptake rates $\left(10-100 \mu \mathrm{l} \mathrm{min}{ }^{-1}\right)$, such as MicroMist (Glass Expansion), a microconcentric nebulizer with desolvator (Aridus, CETAC) ${ }^{4,8}$ or the direct injection high efficiency nebulizer (DIHEN, Meinhard), was investigated for the determination of long-lived radionuclides in highly radioactive waste and in environmental or biomedical samples. ${ }^{12}$ These approaches suffer from a number of disadvantages. The analyzed sample volume still remains relatively high (e.g., $60 \mu \mathrm{min}^{-1}$ and $200 \mu \mathrm{l}$ $\min ^{-1}$ for the DIHEN and Micromist, respectively), the nebulization is usually not complete and a portion of the sample remains as radioactive waste, and the oxide formation rate is rather high. ${ }^{13}$

A remedy to these problems may be a further miniaturization of sample introduction into the ICP-MS, allowing the analysis of nanolitre sample volumes in such a way that $100 \%$ transport efficiency is achieved and dead volume minimized. The aim of this work is to develop a nanovolume (50-nl level) flow injection analysis using a total consumption nebulizer 


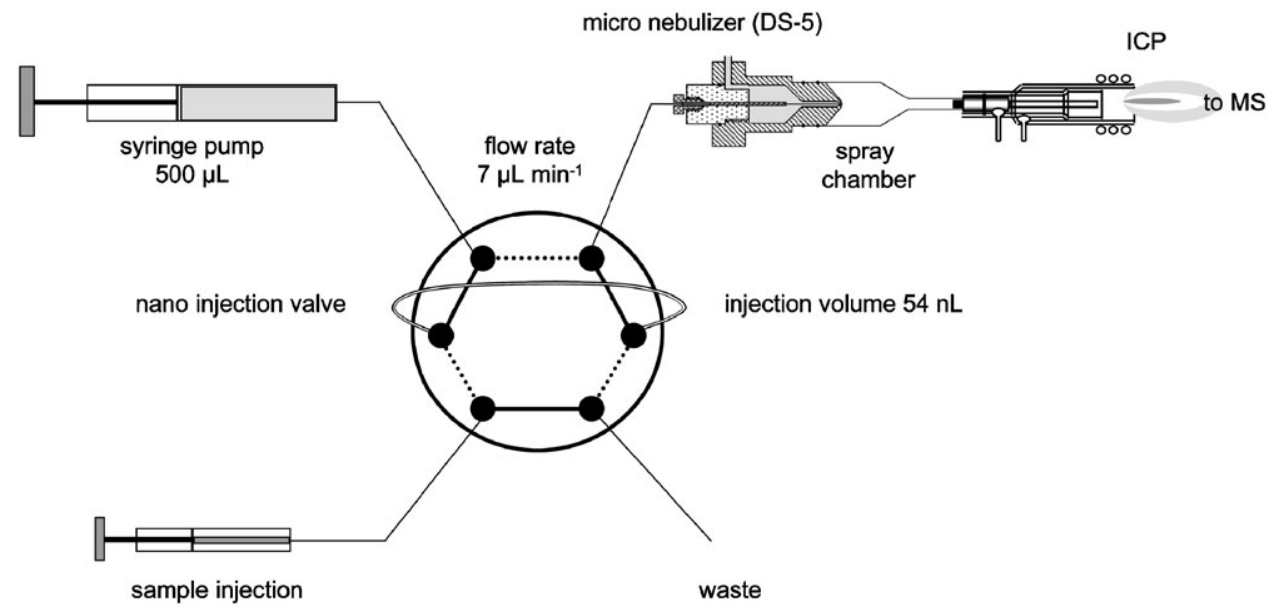

Fig. 1 Experimental setup of nano-volume flow injection ICP-SFMS system.

operating at uptake rates significantly below the $10 \mu \mathrm{min}^{-1}$ level. In terms of analytical performance the objectives set included (i) to obtain the lowest ever reported absolute detection limits for uranium and plutonium in the low attogram range and (ii) to demonstrate the feasibility of precise and accurate isotope ratio determination using short $(<5 \mathrm{~s})$ transient signals.

\section{Experimental}

\section{Instrumentation}

A double-focusing sector field ICP-MS (ICP-SFMS, ELEMENT, Finnigan MAT, Bremen, Germany) was used. The ICP torch was shielded with a grounded platinum electrode (GuardElectrode $^{\mathrm{TM}}$, Finnigan MAT). Solution introduction into the ICP-SFMS was performed using a nano-volume flow injection with a microflow total consumption nebulizer DS-5 (CETAC, Omaha, NE, developed by Schaumlöffel et al. ${ }^{14}$ ) fitted in a low-dead-volume $\left(8 \mathrm{~cm}^{3}\right)$ single pass spray chamber. A low and constant carrier flow rate of $7 \mu \mathrm{min}^{-1}$ was provided by a highprecision syringe pump (CMA-100, Carnegie Medicine, Solna, Sweden). Nano-volume flow injection was achieved by an ultralow dead volume nano-injection valve $\mathrm{CN}-2$ (Valco Instruments, Houston, TX). The sample loop was an $8 \mathrm{~cm}$ long and $20 \mu \mathrm{m}$ id fused silica capillary with an internal volume of $25 \mathrm{nl}$. Taking into account the internal port-to-port volume of the valve of $29 \mathrm{nl}$ specified by the valve manufacturer, the total sample volume was $54 \mathrm{nl}$. All the tubing between the syringe pump, the injection valve and the nebulizer was made of $75 \mu \mathrm{m}$ id fused silica capillaries. Zero-dead-volume connections were achieved by a precise flat cut of the fused silica capillaries which allowed the abutting of the capillaries in the fittings. The experimental setup is shown in Fig. 1. All measurements were performed under optimized conditions with respect to gas flow rates, rf power, torch position and ion lens settings, which are summarized in Table 1.

\section{Standards and reagents}

A laboratory standard solution of uranium (NBS 3164) with the natural isotopic abundance $\left(1 \mathrm{ng} \mathrm{ml}^{-1}\right)$ was used for optimization of the experimental parameters and the study of the oxide formation rates. The precision and accuracy of the ${ }^{235} \mathrm{U} /{ }^{238} \mathrm{U}$ isotope ratio measurement was examined using a NIST standard reference solution U350 (National Institute of Standards and Technology, Gaithersburg, MD) and a CCLU500 (Laboratory Isotope Standard, Nuclear Research Center, Prague, Czech Republic) ${ }^{15}$ uranium solution with an isotopic ${ }^{235} \mathrm{U} /{ }^{238} \mathrm{U}$ ratio of 0.99991 . A NIST standard reference solution U020 was used for mass bias correction.
Five calibration standards solutions were prepared by dilution of $1 \mathrm{ng} \mathrm{ml}^{-1}$ aqueous uranium and ${ }^{242} \mathrm{Pu}$ (NIST SRM $4334 \mathrm{~F}$ ) to $100,200,500,800$ and $1000 \mathrm{pg} \mathrm{ml}^{-1}$ of uranium and $1,2,510$ and $30 \mathrm{pg} \mathrm{ml}^{-1}$ of plutonium. The solutions were diluted with high purity deionized water $(18 \mathrm{M} \Omega \mathrm{cm})$, obtained from a Milli-Q-Plus water purifier (Millipore Billerica, MA).

All the chemicals used were of supragrade quality (Merck, Darmstadt, Germany). Nitric acid was further purified by sub-boiling distillation.

\section{Samples and sample preparation}

A contaminated urine sample collected from healthy adult volunteers in containers previously washed repeatedly with $2 \%$ $v / v$ nitric acid was investigated. A 1-ml urine sample was microwave-digested and further preconcentrated to $180 \mu \mathrm{l}$ by evaporation, resulting in a preconcentration factor of 5.6.

For the determination of plutonium a $10-\mathrm{L}$ sample of tap water was acidified with nitric acid to $\mathrm{pH} 2$, spiked with $4 \mathrm{pg}$ of ${ }^{242} \mathrm{Pu}$ and thoroughly mixed. Plutonium was co-precipitated in different steps with $\mathrm{MnO}_{2}$ and with $\mathrm{Fe}(\mathrm{OH})_{3}$ and finally separated using TEVA resin, resulting in a sample volume of $15 \mathrm{ml}$. This sample was further preconcentrated to $125 \mu \mathrm{l}$ by evaporation, which resulted in a total preconcentration factor of 80000 , and analysed by nano-volume FI-ICP-MS.

\section{Results and discussion}

\section{Optimization and performance of the nano-volume FI-ICP-SFMS system}

The experimental parameters of the DS-5 nebulizer were optimized in respect of maximum ion intensity and minimum

Table 1 Optimized instrumental parameters of the nano-volume FI-ICP-SFMS system

\begin{tabular}{ll}
\hline Nebulizer & DS-5 \\
\hline Spray chamber & $\begin{array}{l}\text { Low-dead volume, single pass, } \\
\text { quartz } \\
1200\end{array}$ \\
RF power/W & 18 \\
Cooling gas flow rate $/ \mathrm{L} \mathrm{min}^{-1}$ & 1.2 \\
Auxiliary gas flow rate $/ \mathrm{L} \mathrm{min}$ & -1 \\
Nebulizer (carrier) gas flow & 1.3 \\
$\quad$ rate $/ \mathrm{L}$ min & \\
Solution uptake rate $/ \mu 1 \mathrm{~min}^{-1}$ & 7 \\
Ion extraction lens potential/V & -2000 \\
Mass resolution, $(\mathrm{m} / \Delta m)$ & 300 \\
Scanning mode & Peak hopping \\
\hline
\end{tabular}


oxide of uranium formation rate by continuous flow introduction of a sample solution via a syringe pump at microlitre flow rates. The detection limits and the linearity were determined in the optimum conditions for uranium and plutonium in the flow-injection mode using a 54-nl injection loop.

Nebulizer performance. The effect of the ICP radiofrequency power on the sensitivity (Fig. 2(a)) is similar to other nebulizers (with a maximum sensitivity at about $1000 \mathrm{~W}$ ) because the introduction of aqueous solution at the flow-rates characteristic of a DS-5 nebulizer does not influence the ICP. In contrast to other nebulizers, the ion intensity of uranium $\left({ }^{238} \mathrm{U}^{+}\right)$measured as a function of the nebulizer gas flow rate (Fig. 2(b)) is practically constant in the $1.1-1.4 \mathrm{~L} \mathrm{~min}^{-1}$ range after an increase between 1.00 and $1.05 \mathrm{~L} \mathrm{~min}^{-1}$. This unique behavior indicates a complete evaporation of the introduced solution (virtually no aerosol present!) at nebulizer gas flow rates higher than $1.05 \mathrm{~L} \mathrm{~min}^{-1}$. The gas phase introduction results in a remarkable plasma stability because of the absence of coldspots induced by larger aerosol droplets. Furthermore, complete evaporation and thus total consumption of the introduced solution by the DS-5 nebulizer was recently demonstrated elsewhere ${ }^{14}$ and is also confirmed by the linearity of the intensity response in the $2.5-7 \mu \mathrm{min}^{-1}$ range (Fig. 2(c)).

Oxide formation rate. An important parameter of the quality of sample introduction into an ICP-MS is the level of oxide formation. The formation of oxide ions of long-lived radionuclides in ICP-MS using different nebulizers was studied by Becker and Dietze. ${ }^{16}$ Fig. 3(a) shows a similar effect of the rf power on the oxide formation as for the Micromist nebulizer but at a twice lower level at low $(<1.1 \mathrm{~kW})$ rf power values. Owing to a gas-like sample introduction discussed above the oxide formation rate using the DS- 5 nebulizer is less than $2 \%$ at the optimum operating conditions. This is significantly less than that of the DIHEN nebulizer ${ }^{13}$ and also of the MicroMist nebulizer. ${ }^{16}$ Contrary to the situation with the latter, this low

(a) $\stackrel{\circ}{0}$

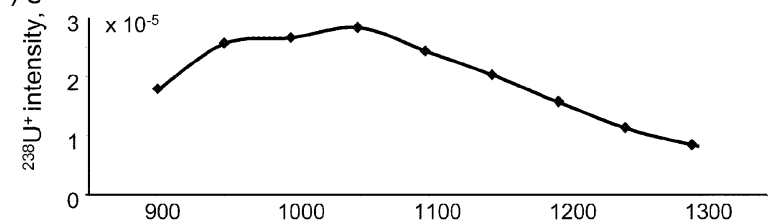

(b) $\stackrel{\circ}{\circ}$

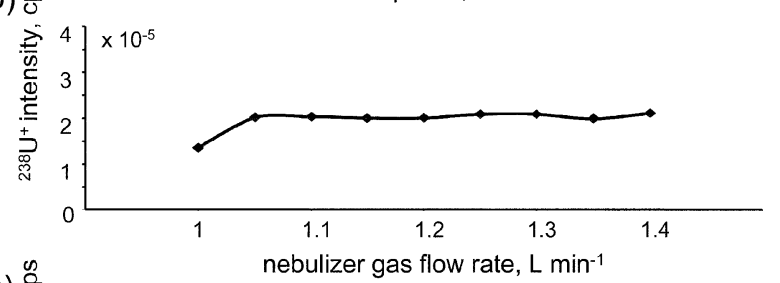

(c) $\stackrel{\circ}{\circ}$

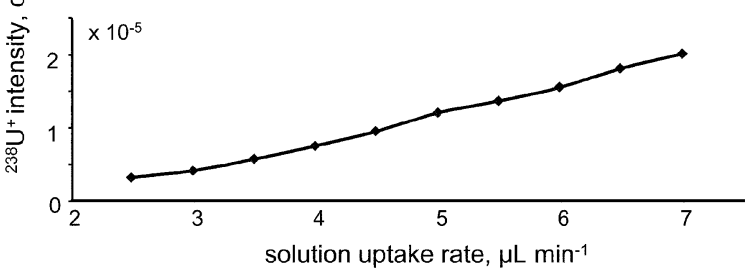

Fig. 2 Effect of: (a) ICP rf power (nebulizer gas flow rate: $1.3 \mathrm{~L} \mathrm{~min}^{-1}$; sample uptake rate: $7 \mu \mathrm{min}^{-1}$ ); (b) nebulizer gas flow rate (rf power: $1200 \mathrm{~W}$; sample uptake rate: $7 \mu \mathrm{min}^{-1}$ ); (c) sample uptake rate (rf power: $1200 \mathrm{~W}$; nebulizer gas flow rate: $1.3 \mathrm{~L} \mathrm{~min}^{-1}$ ) on the sensitivity for uranium $\left({ }^{238} \mathrm{U}^{+}\right)$in ICP-SFMS using the DS-5 nebulizer in the continuous flow sample introduction mode.
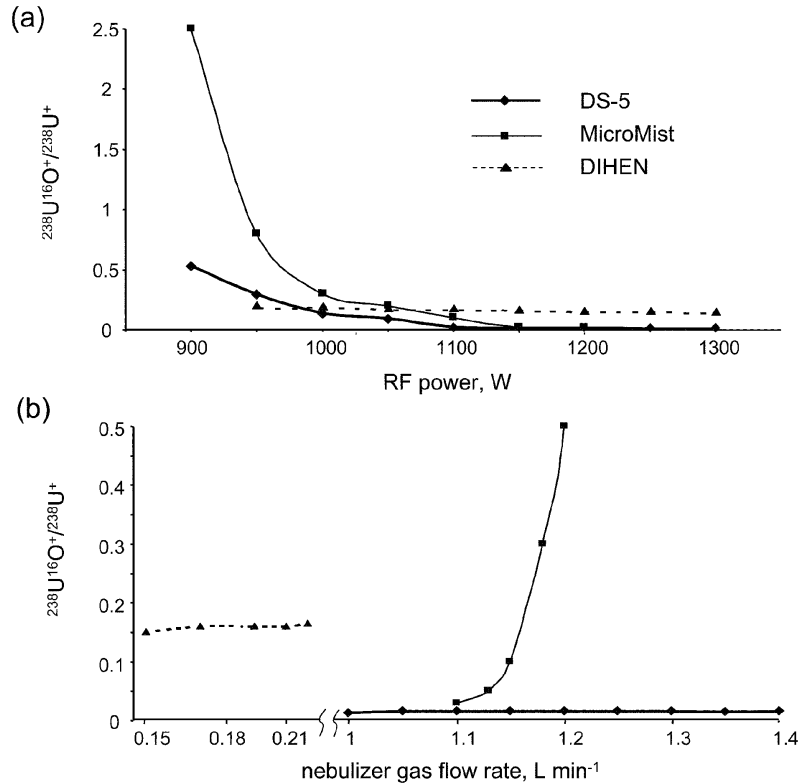

Fig. 3 Comparison of the relative oxide formation rates for uranium in ICP-SF-MS using the DS-5 (bold line), the MicroMist (thin line) and the DIHEN (broken line) nebulizer: (a) effect of the ICP rf power (solution uptake rate DS-5: $7 \mu \mathrm{l} \mathrm{min}{ }^{-1}$; Micromist: $85 \mu 1 \mathrm{~min}^{-1}$; DIHEN: $60 \mu \mathrm{l} \mathrm{min}^{-1}$ ); (b) effect of the nebulizer gas flow rate (solution

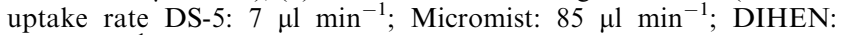
$\left.60 \mu 1 \min ^{-1}\right)$

oxide formation rate remains stable as a function of the nebulizer gas flow rate (Fig. 3(b)). The level of oxide formation also remains stable (between $0.7 \%$ and $1.4 \%$ ) as a function of the sample uptake in the $2.5-7 \mu 1 \mathrm{~min}^{-1}$ range.

Sensitivity. An important parameter to compare different nebulizers is the absolute sensitivity (number of counts per femtogram of analyte) obtained with the same ICP mass spectrometer. Table 2 summarizes the sensitivities reported for the different types of nebulizer for the uranium determination using double-focusing sector field ICP-MS. The outstanding performance of the DS- 5 nebulizer can be explained by the high sample transport efficiency (total consumption) and high ionization efficiency (absence of aerosol). With the increasing solution uptake rate the absolute sensitivity of a nebulizer decreases because the portion of the sample lost to the waste increases and the degrading quality of the aerosol decreases the ionization. Only the Aridus nebulizer with desolvation shows a similar absolute sensitivity. The DIHEN nebulizer features the total sample consumption but the quality of aerosol at an uptake rate of $60 \mu \mathrm{min}^{-1}$ negatively affects the ionization efficiency and thus the absolute sensitivity.

Table 2 Comparison of the absolute sensitivity of different nebulizer types for ${ }^{238} \mathrm{U}^{+}$measured with ICP-SFMS

\begin{tabular}{lllll}
\hline & $\begin{array}{l}\text { Solution } \\
\text { uptake } \\
\text { rate } / \mathrm{ml} \mathrm{min}^{-1}\end{array}$ & $\begin{array}{l}\text { Sample } \\
\text { volume/ml }\end{array}$ & $\begin{array}{l}\text { Absolute } \\
\text { sensitivity } \\
\text { counts/fg }\end{array}$ & Ref. \\
\hline Nebulizer & 0.007 & $0.0005^{a}$ & 2418 & This work \\
DS-5 & 0.06 & 0.12 & 1680 & 13 \\
q-DIHEN & 0.1 & 0.2 & 2340 & 17 \\
Aridus & 0.2 & 0.4 & 580 & 17 \\
PFA & 0.2 & 0.4 & 820 & 13 \\
MicroMist & 0.2 & 2 & 97 & 13 \\
Meinhardt & 1 & & & \\
${ }^{a}$ Using flow injection. & & & \\
\hline
\end{tabular}


(a)

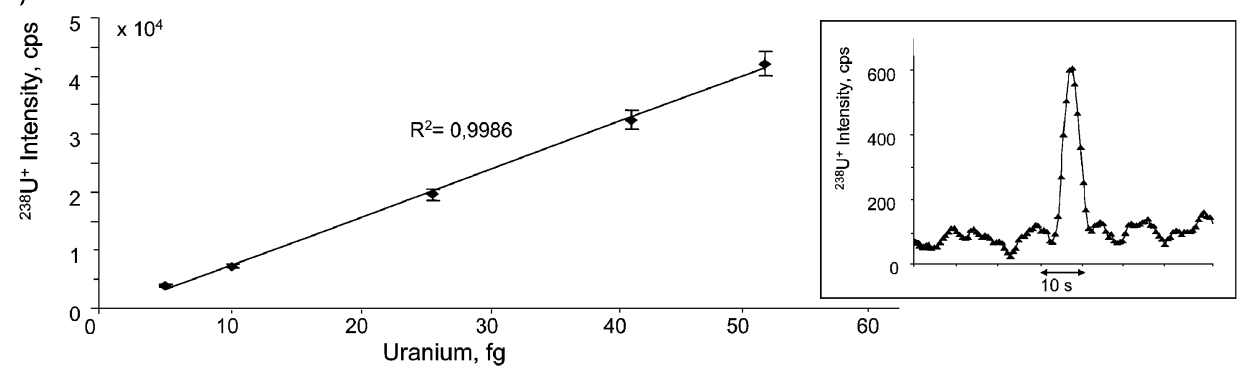

(b)

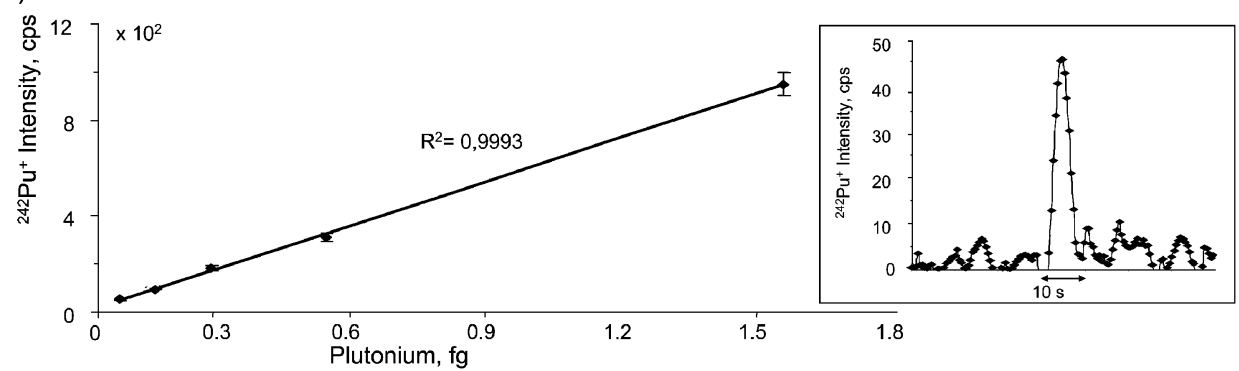

Fig. 4 Calibration curves for the determination of: (a) ${ }^{238} \mathrm{U}$ and (b) ${ }^{242} \mathrm{Pu}$, using nano-volume flow injection ICP-SFMS. The signals shown in the insets correspond to the injection (54 nl) of $10 \mathrm{ng} \mathrm{L}^{-1}$ uranium and $1 \mathrm{ng} \mathrm{L}^{-1}$ plutonium.

\section{Detection limits in the flow-injection mode}

The insets in Fig. 4(a) and 4(b) show the transient signals of ${ }^{238} \mathrm{U}^{+}$and ${ }^{242} \mathrm{Pu}^{+}$for an injection of $54 \mathrm{nl}$ of aqueous solutions containing $10 \mathrm{pg} \mathrm{ml}^{-1}$ (540 ag absolute) and $1 \mathrm{pg} \mathrm{ml}^{-1}(54 \mathrm{ag}$ absolute), of uranium and ${ }^{242} \mathrm{Pu}$, respectively, and demonstrate the very high sensitivity of the nano-volume FI-ICP-SFMS developed. The calibration curves (Fig. 4(a) and 4(b)) are linear in the low femtogram range for ${ }^{238} \mathrm{U}$ and in the subfemtogram range for ${ }^{242} \mathrm{Pu}$. The relative and absolute limits of detection for ${ }^{238} \mathrm{U}$ and ${ }^{242} \mathrm{Pu}$ measured with the developed nano-volume FI-ICP-SFMS system are summarized in Table 3 . Whereas the concentration limits of detection in $54 \mathrm{nl}$ sample volume were found to be 1.6 and $0.3 \mathrm{pg} \mathrm{ml}^{-1}$, the absolution detection limits were at 91 and 15 ag $\left(10^{-18} \mathrm{~g}\right)$ for uranium and plutonium, respectively. The latter correspond to the number of atoms of $\sim 230000$ and $\sim 38000$ for uranium and ${ }^{242} \mathrm{Pu}$, respectively, and are, to our best knowledge, the lowest ever reported.

\section{Uranium isotope ratio measurements by nano-volume FI-ICP-SFMS}

The precision and accuracy for isotope ratio measurements of uranium measured by nFI-ICP-SFMS were studied for 10 repeated measurements using $100 \mathrm{pg} \mathrm{ml}^{-1}$ solutions of NIST U350 and CCLU-500 isotopic standard reference materials. Fig. 5 shows an example of the recorded results for the CCLU500 isotope standard material with regard to ${ }^{235} \mathrm{U}^{+},{ }^{238} \mathrm{U}^{+}$and the ${ }^{235} \mathrm{U}^{+} /{ }^{238} \mathrm{U}^{+}$ratio. The precision of transient signal measurements on CCLU-500 laboratory standards $(n=10)$ was better than $2.5 \%$ (RSD).

The results obtained for the NIST U350 material are summarized in Table 4. They demonstrate, considering the very

Table 3 Relative and absolute detection limits for ${ }^{238} \mathrm{U}$ and ${ }^{242} \mathrm{Pu}$ measured with the developed nano-volume FI-ICP-SFMS system

\begin{tabular}{lllll}
\hline & $\begin{array}{l}\text { Relative } \\
\text { detection } \\
\text { limits } \\
10^{-12} \mathrm{~g} \mathrm{ml}^{-1}\end{array}$ & $\begin{array}{l}\text { Absolute } \\
\text { detection } \\
\text { limits } \\
10^{-18} \mathrm{~g}\end{array}$ & $\begin{array}{l}\text { Absolute } \\
\text { detection } \\
\text { limits } \\
10^{-19} \mathrm{~mol}\end{array}$ & $\begin{array}{l}\text { Estimated } \\
\text { number } \\
\text { of atoms }\end{array}$ \\
\hline${ }^{238} \mathrm{U}$ & 1.6 & 91 & 3.8 & $\sim 230000$ \\
${ }^{242} \mathrm{Pu}$ & 0.3 & 15 & 0.6 & $\sim 38000$ \\
\hline
\end{tabular}

small sample volume analyzed (54 $\mathrm{nl})$, the excellent performance of nano-volume FI-ICP-SFMS. The precision of isotope ratio measurement increased with the decreasing of isotope ratio. The most accurate (RSD of $0.7 \%$ ) value was measured for the ${ }^{235} \mathrm{U} /{ }^{238} \mathrm{U}$ ratio. The precision of the measurements of uranium isotope ratios in the NIST U350 material was in the low \% range.

\section{Determination of uranium isotope ratios in urine}

The high sensitivity of the analytical procedure developed allowed the determination of the ${ }^{235} \mathrm{U} /{ }^{238} \mathrm{U}$ isotope ratio in a urine sample at the ultratrace level. In order to avoid clogging of the nebulizer, the sample was microwave digested. A blank run was performed prior to analysis. Owing to a very small injection volume (54 $\mathrm{nl})$ in the FI mode matrix effects, such as clogging of the nebulizer capillary or deposits on the skimmer cone, were minimized, allowing the preconcentration by evaporation. The value obtained, $0.037 \pm 0.005$, was validated (the value obtained $0.048 \pm 0.006$ ) using a PFA-100 (Elemental

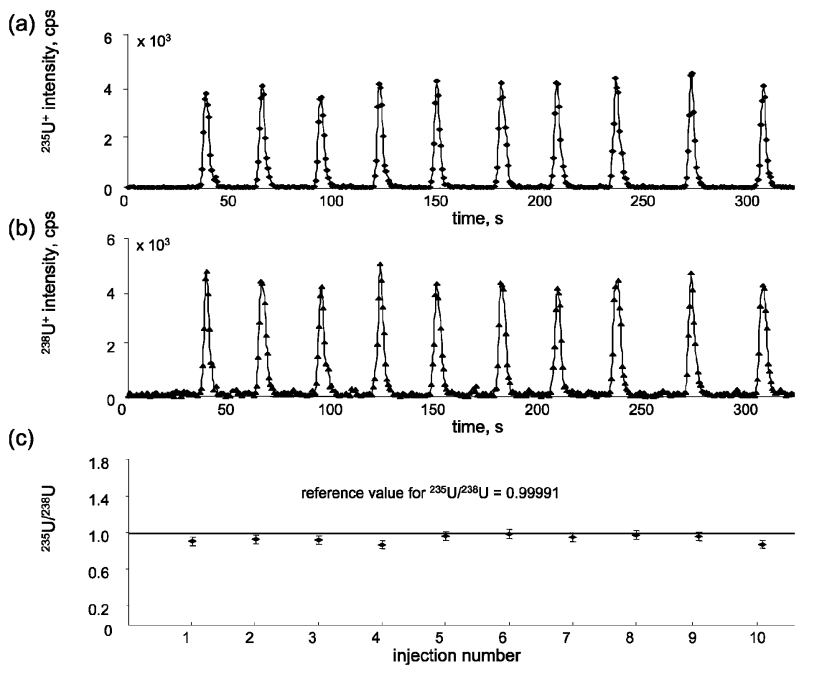

Fig. 5 Flow-injection signals of: (a) ${ }^{235} \mathrm{U}^{+}$and (b) ${ }^{238} \mathrm{U}^{+}$recorded for the analysis of the CCLU-500 isotope standard reference material; (c) the calculated ${ }^{235} \mathrm{U} /{ }^{238} \mathrm{U}$ isotopic ratio compared with the reference value. 
Table 4 Relative standard deviation and accuracy of uranium isotope ratio measurement in the NIST U350 material (10 injections)

\begin{tabular}{lcccc}
\hline & $\begin{array}{c}\text { Experi- } \\
\text { mental }\end{array}$ & Certified & $\begin{array}{c}\text { Relative } \\
\text { standard } \\
\text { deviation (\%) }\end{array}$ & Accuracy (\%) \\
\hline${ }^{235} \mathrm{U} /{ }^{238} \mathrm{U}$ & 0.546974 & 0.54648800 & 2.3 & 0.7 \\
${ }^{234} \mathrm{U} /{ }^{238} \mathrm{U}$ & 0.003703 & 0.00387900 & 3.2 & -4.5 \\
${ }^{236} \mathrm{U} /{ }^{238} \mathrm{U}$ & 0.002736 & 0.00259800 & 8.0 & 5.2 \\
\hline
\end{tabular}

Scientific, Inc., Omaha, NE, USA) nebulizer and continuous flow nebulization mode. The precision of both measurements is very similar, which demonstrates the feasibility of very short transient signal measurement with a sector field instrument. The comparison of the measured value with the natural ${ }^{235} \mathrm{U} /{ }^{238} \mathrm{U}$ isotope ratio $(0.00725)$ demonstrates unambiguously that the origin of contamination was enriched uranium.

\section{Determination of plutonium in water}

The analytical setup was applied to the determination of plutonium in tap water spiked with ${ }^{242} \mathrm{Pu}$ at the subfemtomolar level. Plutonium was preconcentrated from a 10-1 volume of water down to a volume of $125 \mu \mathrm{l}$ (enrichment factor of 80000 ) by a matrix separation and preconcentration procedure as described above. The concentration determined by nanovolume FI-ICP-SFMS was 230 ag per $\mathrm{ml}$, which meant recovery at the $60 \%$ level. The detection limit of the overall procedure was $6 \times 10^{-18} \mathrm{~g} \mathrm{ml}^{-1}\left(6 \mathrm{ag} \mathrm{ml}^{-1}\right)$, taking in account an enrichment factor of 80000 and a recovery of $60 \%$. Future studies on the applicability of this method to plutonium measurements in real samples are planned.

\section{Conclusions}

The nanolitre volume flow-injection analysis using a double focusing sector field ICP mass spectrometer offers the highest absolute sensitivity ever reported for uranium and plutonium. After analyte enrichment the detection limits of plutonium are in the ag ml $\mathrm{m}^{-1}$ concentration range. The very small sample consumption indicates the potential of the method developed for the analysis of small amounts of rare, toxic or radioactive samples. The precision of isotope ratio determination can be further improved using multiple collector ICP mass spectrometry without any change in the sample introduction setup.

\section{Acknowledgements}

The authors gratefully acknowledge R. Hille for financial support of this work and P. Ostapczuk (both from Department for Safety and Radiation Protection, Research Centre in Jülich) for helpful discussion. The support from the TOXNUC and CNRS ACI NMAC programmes is acknowledged.

\section{References}

1 R. Henry, D. Koller, M. Liezers, O. T. Farmer, C. Barinaga, D. W. Koppenaal and J. Wacker, J. Radioanal. Nucl. Chem., 2001, 249, 103.

2 J. S. Becker, Spectrochim. Acta, Part B, 2003, 58, 1757.

3 M. E. Ketterer, K. M. Hafer, C. L. Link, C. S. Royden and W. J. Hartsock, J. Environ. Radioact., 2003, 67, 191.

4 D. Desideri, M. A. Meli, C. Roselli, C. Testa, S. F. Boulyga and J. S. Becker, Anal. Bioanal. Chem., 2002, 374, 1091.

5 M. Betti, Microchem. J., 2000, 67, 363.

6 M. Agarande, S. Benzoubir, A. M. Neiva-Marques and P. Bouisset, J. Environ. Radioact., 2004, 72, 169.

7 R. N. Taylor, T. Warneke, J. A. Milton, I. W. Croudace, P. E. Warwick and R. W. Nesbitt, J. Anal. At. Spectrom., 2001, 16, 279.

8 M. Zoriy, C. Pickhardt, P. Ostapczuk, R. Hille and J. Becker, Int. J. Mass Spectrom., 2004.

9 I. T. Platzner, Modern Isotope Ratio Measurement, John Wiley, 1997.

10 J. S. Becker, J. Anal. At. Spectrom., 2002, 17, 1172

11 D. Schaumlöffel, Anal. Bioanal. Chem., 2004, 379, 351.

12 J. S. Becker, H.-J. Dietze, J. A. McLean and A. Montaser, Anal. Chem., 1999, 71, 3077.

13 J. A. McLean, J. S. Becker, S. F. Boulyga, H. J. Dietze and A. Montaser, Int. J. Mass Spectrom., 2001, 208, 193.

14 D. Schaumlöffel, J. Ruiz Encinar and R. Lobinski, Anal. Chem., 2003, 75, 6837 .

15 H.-J. Dietze, Berichte des Zentralinstitut fuer Isotopen und Strahlenforschung der Akademie der Wissenschaften der DDR, 1979, vol. 27.

16 J. S. Becker and H.-J. Dietze, Int. J. Mass Spectrom., 2000, 202, 69.

17 M. V. Zoriy, L. Halicz, M. E. Ketterer, C. Pickhardt, P. Ostapczuk and J. S. Becker, J. Anal. At. Spectrom., 2004, 19, 362. 